\title{
6. Entwicklung des Verhältnisses zur DDR bis Anfang 1961
}

\section{Historischer Hintergrund und unterschiedliche Sichtweisen}

Die SED-Führung entwickelte sich in den fünfziger Jahren von einem Satellitenregime, das bei der Staatsgründung 1949 weiterhin voll dem sowjetischen Besatzungsregime unterlag und ausdrücklich nur administrative Befugnisse erhalten hatte, zum Juniorpartner mit wachsendem Selbstbewußtsein gegenüber der UdSSR. Schon 1953 hatten die Nachfolger Stalins geprüft, ob nicht die „Autorität der DDR “ in der Bevölkerung durch Kompetenzübertragungen gestärkt werden solle. Angesichts der galoppierenden inneren Krise waren sie freilich zu der Auffassung gelangt, sie müßten zunächst durch einen aufgenötigten „Neuen Kurs“ Ordnung schaffen. Nach dem Aufstand am 17. Juni hatten sie die Politik der Eingriffe zusätzlich verstärkt, ehe sie dem Regime im März 1954 im Rahmen des Besatzungsrechts souveräne Rechte zuerkannten. Der Vorbehalt wurde ausdrücklich wiederholt, als sie der DDR im September 1955 in Vertragsform größeren politischen Freiraum zubilligten. In den Jahren 1957 und 1958 wurde die Präsenz sowjetischer Instrukteure und Berater verringert.

Das Berlin-Ultimatum vom November 1958 stellte eine grundlegende Veränderung in Aussicht. Chruschtschow bekundete den Willen, das Besatzungsrecht völlig aufzuheben. Er hatte dabei zwar die Westmächte im Auge, deren Rechtsposition und Militärpräsenz in West-Berlin unhaltbar gemacht werden sollte, doch verband sich damit die Konsequenz, daß die UdSSR gegenüber der DDR keine übergeordneten Okkupationsbefugnisse mehr besitzen würde. Anforderungen an die ostdeutsche Seite waren demnach nur noch mit der Pflicht zu kommunistischer Solidarität und zu allianzkonformem Verhalten zu begründen. Ulbricht nutzte die neuen Möglichkeiten. Er versuchte zunehmend, unter Berufung auf den sowjetischen Standpunkt die Restbestände des Vier-Mächte-Status, vor allem die rechtliche Basis für die Präsenz der Westmächte in Berlin und für freien $\mathrm{Zu}$ gangsverkehr, auszuhöhlen, ohne daß bereits vertragliche Vereinbarungen darüber vorlagen. Wie in der Forschung übereinstimmend festgestellt wurde, zog das Spannungen und Konflikte mit der UdSSR nach sich.

Die mit dem Thema befaßten Historiker sind dabei zu unterschiedlichen Ansichten über die Relation der wechselseitigen Einflußnahme gelangt. Hope Harrison ist sich zwar des enormen Machtgefälles zwischen UdSSR und DDR bewußt, sieht aber darin keinen Hinderungsgrund für die Annahme, daß Ulbricht seinen Willen Chruschtschow aufnötigen konnte. Als Hebel hätten ihm gedient: die einseitige Schaffung vollendeter Tatsachen, der Hinweis auf chinesische „Papier- 
tiger"-Vorwürfe an die Adresse des Kreml, die sowjetische These von der entscheidenden Rolle des ostdeutschen Staates im globalen Systemwettstreit und geschicktes Kontern und Sabotieren der Politik Moskaus. Vor allem habe er es verstanden, die Schwäche der DDR durch die Perspektive drohenden Zusammenbruchs in Verhandlungsmacht umzuwandeln. Demnach geriet Chruschtschow immer wieder unter übermächtigen Druck: Der kleine Verbündete habe ihn auf diese Weise gegen seinen Willen vorangetrieben. ${ }^{1}$ Ähnlich urteilt Marc Trachtenberg. ${ }^{2}$ Michael Lemke dagegen kommt zu dem Schluß, das wechselseitige Verhältnis sei durch die Tatsache bestimmt worden, daß die SED-Führung in jeder Hinsicht vom Schutz und der Unterstützung der UdSSR abhängig gewesen sei. Demnach konnte Ulbricht zwar seine Position vertreten und durchzusetzen suchen, mußte sich aber fügen, wenn der Kreml das für nötig hielt. ${ }^{3}$ Auch Detlef Nakath betont, die DDR habe die sowjetischen Interessen „immer zuerst in Rechnung“ stellen müssen. In „jeder wichtigen Frage“ sei sie zur Konsultation mit Moskau genötigt gewesen, und dort habe man die Entscheidung „de facto “ getroffen. ${ }^{4}$ Für Aleksandr Fursenko, der sich auf Dokumente aus Moskauer Archiven stützt, ist die DDR ein „Satellit des sowjetischen Blocks“ gewesen, obwohl man „die Rolle“ ihrer Führer bei den Entscheidungen zur deutschen Frage „nicht bagatellisieren“ dürfe. ${ }^{5}$

\section{Ausgangslage}

Für die SED galt, daß alle Aktionen und Stellungnahmen hinsichtlich Deutschlands und Berlins mit Moskau abzustimmen waren. ${ }^{6}$ Das verstand sich für Chruschtschow von selbst; ihm stellte sich das beiderseitige Vorgehen dar als eine koordinierte Politik, bei der jeder seinen speziellen Part zu übernehmen hatte. Der Kreml schützte die DDR durch seine militärische Macht vor dem Verlangen

1 Hope M. Harrison, Die Berlin-Krise und die Beziehungen zwischen der UDSSR und der DDR, in: G. Wettig (Hrsg.), Die sowjetische Deutschland-Politik in der Ära Adenauer, Bonn 1997, S. 105122; Hope M. Harrison, Driving the Soviets up the Wall: A Super-Ally, a Superpower, and the Building of the Berlin Wall, 1958-1961, in: Cold War History, Vol. I, Nr. 1, August 2000, S. 53-74.

2 M. A. Trachtenberg, Constructed Peace. The Making of the European Settlement 1945-1963, Princeton/N.J. 1999, S. 321-324.

3 M. Lemke, Die Berlinkrise, a.a.O., S. 36-92; Michael Lemke, Die SED und die Berlin-Krise 1958 bis 1963, in: Gerhard Wettig, Die sowjetische Deutschland-Politik in der Ära Adenauer, Bonn 1997, S. $123-137$.

4 Detlef Nakath, Von der Konfrontation zum Dialog. Zum Wandel des Verhältnisses zwischen beiden deutschen Staaten, in: Aus Politik und Zeitgeschichte. Beilage zur Wochenzeitung „Das Parlament", B 43/2003, 3. 11. 2003, S. 42.

5 A. A. Fursenko, Kak byla postroena berlinskaja stena, in: Istoričeskie zapiski, 4/2001 (122), S. 73.

6 In den Akten finden sich immer wieder Belege dafür, daß die DDR-Führung gehalten war, den Kreml vor jedem Schritt genau von dem geplanten Vorgehen in Kenntnis zu setzen und um „Bemerkungen“ dazu nachzusuchen. So wandte sich Ulbricht am 4.5.1960 an den sowjetischen Botschafter mit dem Entwurf einer Note an die UdSSR und die Westmächte, mit der er gegen „Provokationen der Westberliner Polizei“ auf dem S-Bahn-Gelände protestierte (W. Ulbricht an M. G. Pervuchin, 4. 5. 1960, SAPMO-BArch, DY 30/3507, Bl. 295-302). Ein Schreiben der DDR-Regierung an Adenauer konnte erst abgesandt werden, nachdem Chruščëv es als „zeitgemäß und nützlich“ gebilligt hatte (N. S. Chruščëv an W. Ulbricht, SAPMO-BArch, DY 30/3507, Bl. 15). 
nach Wiedervereinigung in Freiheit und gab so dem Verbündeten Sicherheit nach innen und außen. Der von ihm unterstützte Standpunkt, die nationale Einheit könne nur in Gesprächen zwischen beiden Staaten vereinbart werden, lief auf ein Veto gegen die Bonner Forderung nach freien Wahlen hinaus. Die Anerkennung der DDR sollte allen Verhandlungen über die deutsche Frage zugrunde gelegt werden. Nur was Ost-Berlin akzeptierte, konnte demnach beschlossen werden. Angesichts der gegensätzlichen Standpunkte beider Staaten war von vornherein nicht mit einer Übereinkunft zu rechnen. Die östliche Propaganda stellte das westdeutsche Nein zu einem solchen Dialog als Beweis für die Ablehnung der staatlichen Einheit heraus. Die DDR müsse „zunächst die inneren Voraussetzungen für die Wiedervereinigung schaffen“. Dazu sollten „sich die Kräfte des Volkes gegen den deutschen Militarismus zusammenschließen, die Führung der Adenauerpartei isolieren und bei den Bundestagswahlen der Adenauerpartei eine Niederlage bereiten." ${ }^{7}$

Wenn es um die Abwehr der Forderung nach staatlicher Einheit unter westlichdemokratischem Vorzeichen ging, stimmten die Interessen von UdSSR und DDR voll überein. Chruschtschow ging zudem davon aus, aufgrund kommunistischer Gemeinsamkeit bestehe Harmonie in jeder Hinsicht. Durch Abstimmung der Positionen zwischen beiden sozialistischen Staaten werde man stets zu einer Verständigung gelangen. Nach den Erschütterungen in Ostmitteleuropa 1956, die er als Protest gegen fremdnationale Bestimmung deutete, suchte er das Bedürfnis der verbündeten Länder nach Eigenständigkeit durch Zugeständnisse zu befriedigen, um damit die Ressentiments gegen die sowjetische Hegemonialmacht abzubauen. Er lockerte die Zügel in der Erwartung, dadurch das sozialistische Lager zu stabilisieren. Auf dem XXI. KPdSU-Parteitag verzichtete er darauf, den Anspruch auf die „führende Rolle“ im sozialistischen Lager ausdrücklich zu erneuern. Es war nur noch von einer „besonders wichtigen Rolle“ der UdSSR in der kommunistischen Bewegung die Rede. ${ }^{8}$ Die bisherige „Anleitung“ wollte er deswegen nicht aufgeben, wohl aber weniger intensiv und sichtbar ausüben. Zu Anfang schien das gegenüber der DDR wie beabsichtigt zu funktionieren. Ulbricht und seine Mitarbeiter unterbreiteten Chruschtschow bzw. den zuständigen Moskauer Stellen weiterhin die außenpolitisch wichtigen Entwürfe, vor allem die Formulierungen zur Deutschland- und Berlin-Politik, zur vorherigen Beurteilung9 und suchten sich anfangs stets im voraus mit dem Kreml abzustimmen. Dieser nahm manchmal erhebliche Korrekturen vor, ${ }^{10}$ während anderes ohne Veränderung durchging. 11

7 W. Ulbricht an G. M. Puškin, 11. 5. 1956, SAPMO-BArch, DY 30/3496, Bl. 1.

8 ZK der KPdSU an das ZK der SED, 23. 1. 1959, SAPMO-BArch, NY 4182/1206, Bl. 22-30.

9 Siehe z.B. Gespräch M. G. Pervuchin - W. Ulbricht, 9. 1. 1959, RGANI, 5, 49, 279 (rolik 8945), Bl. 5-10.

10 Siehe W. Ulbricht an N. S. Chruščëv (mit Anlagen), 1. 10. 1958, RGANI, 5, 49, 93 (rolik 8879), Bl. 1-44 (russ. Übers.), 45-134 (dtr. Originaltext); Aktenvermerk Kundermann über Gespräch Winzer - Astavin in der sowjetischen Botschaft am 21. 11. 1958, PA-MfAA, A 133, Bl. 328; Bericht von M. G. Pervuchin über die Gespräche Chruščëv - Ulbricht am 11./12. 4. 1959, 19. 4. 1959, RGANI, 5, 49, 279 (rolik 8945), Bl. 119 f.

11 Anweisung des ZK der KPdSU an M. Pervuchin [Auftrag, Ulbricht über das Einverständnis mit dem Text eines Briefes des ZK der SED an die sozialdemokratischen Arbeiter in Westdeutschland zu unterrichten], o.D. [Ende Juli 1960], RGANI, 5, 49, 279 (rolik 8945), Bl. 161. 
Anders als Stalin war Chruschtschow bei der Koordination in gewissem Umfang zu Gegenseitigkeit bereit. Hatte früher nur die SED-Führung ihre Stellungnahmen der anderen Seite vor Beschlußfassung vorgelegt, so wurde Ulbricht nun auch seinerseits öfters konsultiert, wenn es um ihn betreffende außenpolitische Probleme ging. ${ }^{12}$ Selbstverständlich lag die Entscheidung stets allein auf sowjetischer Seite. Der ostdeutsche Parteichef konnte aber Überlegungen einbringen und auf die Gestaltung von Einzelheiten Einfluß nehmen. Nicht unwichtig war, daß er - ein Novum - Dokumente und Informationen über manche ihn interessierende internationale Vorgänge erhielt und auf diese Weise zu einem Urteil über das Vorgehen des Kreml in verschiedenen Fragen befähigt wurde. Die Abschwächung der sowjetischen Dominanz zeigte sich auch in einer verringerten Penetration der ostdeutschen Machtapparate. Vor allem der Staatssicherheit und der Armee wurde nunmehr größere Selbständigkeit zugestanden, doch waren dort weiter - in geringerem Umfang und mit reduzierten Kompetenzen - sowjetische „Berater“ tätig. ${ }^{13}$ Anderswo, so bei der Polizei und im Flugzeugbau, wurden die Experten der UdSSR völlig zurückgezogen. ${ }^{14}$ Das erweiterte die Handlungsfreiheit der DDR nach innen und außen.

Als Chruschtschow das Berlin-Ultimatum formulierte, glaubte er, daß sich an der im wesentlichen reibungslosen Zusammenarbeit nichts ändern werde. Tatsächlich jedoch vollzog sich ein Wandel. Die Befugnisse, die sich der Kreml bis dahin vorbehalten hatte, ${ }^{15}$ hatten die Kontrolle über die Westpolitik der SED-Führung zuverlässig gewährleistet. Ulbricht war es verwehrt worden, den Konflikt mit den Westmächten durch eigenmächtige Schritte in und um Berlin zu verschärfen. Das stand in Frage, als Chruschtschow der DDR einen Anspruch auf Souveränität über ihr gesamtes Territorium, vor allem auch die volle Verfügungsgewalt über die Verkehrswege West-Berlins (einschließlich der Luftkorridore), prinzipiell zubilligte. Wenn die UdSSR, wie beabsichtigt, jede Verantwortung für den Transit künftig von sich wies, brachte sie zwar den Westen in eine schwierige Lage, erlaubte aber zugleich Ulbricht, Maßnahmen nach eigenem Gutdünken zu

12 Bericht Ulbrichts auf der 3. Tagung des ZK der SED, Stenografische Niederschrift, 2. 12. 1958, SAPMO-BArch, DY 30/IV 2/1/11. Bl. 42 [Abstimmung der sowjetischen Noten vom 27.11. 1958 mit der SED]; A. Gromyko an das ZK der KPdSU, 15. 1. 1959, AVPRF, 0742, 4, 33, 59, Bl. $37 \mathrm{f}$. [Hinweis auf Abstimmung der Vereinbarungsentwürfe für die bevorstehende Vier-Mächte-Konferenz mit der SED]; W. Ulbricht an N. S. Chruščëv (mit 2 Anlagen), 27. 2. 1959, AVPRF, 0742, 4, 32, 41, Bl. 71-80 [Modifikationswünsche des SED-Politbüros zu den sowjetischen Vereinbarungsentwürfen]; A. Gromyko an das ZK der KPdSU, 27. 2. 1959, AVPRF, 0742, 4, 32, 41, Bl. 9-11 [Befürwortung der SED-Wünsche].

13 W. Ulbricht an das ZK der KPdSU, 21. 11. 1958, SAPMO-BArch, DY 30/3386, Bl. 29-31; Michael Lemke, Die Berlinkrise 1958 bis 1963. Interessen und Handlungsspielräume der SED im OstWest-Konflikt, Berlin 1995, S. 42-46; Roger Engelmann, Aufbau und Anleitung der ostdeutschen Staatssicherheit durch sowjetische Organe 1949-1959, in: Andreas Hilger/Mike Schmeitzner/Ute Schmidt (Hrsg.), Diktaturdurchsetzung. Instrumente und Methoden der kommunistischen Machtsicherung in der SBZ/DDR 1945-1955, Berichte und Studien [des Hannah-Arendt-Instituts für Totalitarismusforschung] Nr. 35, Dresden 2001, S. 63 f.

14 Persönl. Verschlußsache für W. Stoph, BArch-MArch, ZK 01, Tgb.-Nr. 41/58, 30. 9. 1958, Bl. 87; Persönl. Verschlußsache für W. Stoph, BArch-MArch, ZK 01, Tgb.-Nr. 41/58, 30. 9. 1958, Bl. 194.

15 Vertrag zwischen UdSSR und DDR sowie Briefwechsel zwischen Zorin und Bolz, 20. 9. 1955 (dt. und russ.), in: Dokumente zur Deutschlandpolitik, hrsg. vom Bundesministerium für Gesamtdeutsche Fragen, III. Reihe, Band 1, Frankfurt/Main 1961, S. 368-377. 
treffen, indem er aufgrund der seinem Staat zugebilligten Souveränität für sich das Recht zu unabgestimmter Entscheidung in Anspruch nahm.

\section{Auseinandersetzungen über die Frage der Verständigung mit den Westmächten}

Solange die Westmächte zur vollen Erfüllung seiner Forderungen nicht bereit waren, zögerte Chruschtschow immer wieder von neuem, dem Ultimatum vom November 1958 die Tat folgen zu lassen. Ulbricht war damit zunehmend unzufrieden. Er sah sich in der Erwartung getäuscht, daß Friedensvertrag und Freistadtregelung innerhalb von sechs Monaten mit oder ohne Einverständnis der Westmächte durchgesetzt werden würden, und war der Ansicht. daß die UdSSR verpflichtet war, die westliche Weigerung durch die zugesagte Regelung allein mit der DDR zu beantworten.

Die fundamentale Differenz trat im Juni 1959 offen zutage. Chruschtschow war nach Ablauf der gesetzten Frist von seinem Vorhaben abgerückt, die Westmächte mit dem Separatvertrag zu konfrontieren, und erklärte den SED-Führern, er wolle vorerst auf eine abschließende Lösung der Berlin-Frage verzichten. Durch ein Zwischenabkommen wolle er den Eindruck vermeiden, er suche die andere Seite an die Wand zu drücken und auf Biegen und Brechen zur Erfüllung der Forderungen zu zwingen. Man müsse ihr Zeit lassen. „Die Amerikaner wollen die DDR nicht anerkennen - aus Prestigegründen. Das macht uns nichts aus. Sie haben die Sowjetunion [nach deren Gründung] 16 Jahre lang nicht anerkannt, und $\mathrm{da}$ wollt ihr, daß sie euch nach 10 Jahren anerkennen. Ihr werdet mindestens 17 Jahre warten müssen. “ Wie er hinzufügte, würde Druck nur „die Entspannung stören“, aber nichts einbringen. ${ }^{16}$ Chruschtschow stellte den ostdeutschen „Freunden“ vor Augen, nach Ende der Übergangsfrist werde eine „sehr vorteilhafte Situation" bestehen, die, wie zu entnehmen war, nicht nur der UdSSR, sondern auch der DDR nützen werde. Ulbricht beharrte jedoch auf seinem Standpunkt und verlangte eine verbindliche Festlegung, wann mit der westlichen Präsenz in West-Berlin endgültig Schluß sei. Chruschtschow lehnte dies ab; er wollte hinsichtlich des Zeitpunkts „flexibel“ bleiben. ${ }^{17}$

Ulbricht befürchtete endlose Verzögerungen. Er schlug daher vor, das festgelegte Ziel wenigstens teilweise durchzusetzen. Der Kreml solle die westliche Anregung aufgreifen, die DDR als „Agent der UdSSR“ mit der Abwicklung des Landverkehrs nach West-Berlin unter Einschluß der Militärtransporte zu beauf-

16 Damit stimmt die Tatsache überein, daß die Garantieerklärung, welche die DDR nach einem vor Beginn der Pariser Gipfelkonferenz im Mai 1960 vorgelegten sowjetischen Memorandum gegenüber den Westmächten abgeben sollte, ausdrücklich nicht von der westlichen Bereitschaft zur diplomatischen Anerkennung des ostdeutschen Staates abhängig gemacht wurde (Christian Bremen, Die Eisenhower-Administration und die zweite Berlin-Krise 1958-1961, Veröffentlichungen der Historischen Kommission zu Berlin Bd. 95, Berlin-New York 1998, S. 511).

17 Kratkaja zapis' peregovorov. S partijno-pravitel'stvennoj delegaciej GDR 9 ijunja 1959g., 27.6. 1959 (Datum der Niederschrift), AVPRF, 0742, 4, 31, 33, Bl. 74f., 77, 82 f.; Zapis' peregovorov s partijno-pravitel'stvennoj delegaciej GDR 18 ijunja 1959g., 29. 6. 1959 (Datum der Niederschrift), AVPRF, 0742, 4, 31, 33, Bl. 91. 
tragen. Davon aber wollte Chruschtschow nichts wissen. ${ }^{18}$ Neben seiner generellen Neigung zu einer Politik des Alles-oder-nichts sprachen auch konkrete Überlegungen dagegen. Die Westmächte hatten ihr informelles Angebot an die Bedingung geknüpft, weiter als Besatzungsmächte in den Westsektoren bleiben zu können. Solange das der Fall war, gefährdete die Übergabe von Befugnissen an den Zugangswegen die sowjetische Kontrolle des Verhältnisses zum Westen. Dann konnte das SED-Regime nämlich eigenmächtig Aktionen einleiten, für deren Folgen der Kreml einstehen mußte. Diesem unkalkulierbaren Risiko wollte sich Chruschtschow nicht aussetzen. Erst wenn die westliche Präsenz in Berlin und möglichst ganz Deutschland beseitigt war, durften die „deutschen Freunde“ Kontrollfunktionen - also Macht - an dieser heiklen Stelle ausüben, denn dann konnte von dort kein Konflikt mehr mit den Westmächten ausgehen. ${ }^{19}$

Chruschtschow mußte sich auch in der Folgezeit mit dem Verlangen Ost-Berlins auseinandersetzen, das Ultimatum von 1958 verpflichte zum Abschluß des Separatfriedensvertrags. Ulbricht erneuerte seinen Versuch, Chruschtschow wenigstens zu Teilschritten zu bewegen. Anfang 1960 unterbreitete er die Idee eines „Vorfriedensvertrages“ mit der Bundesrepublik. Dieser sollte dem Westen als Regelung vorgeschlagen werden, die sich sofort verwirklichen lasse, weil er den Einwand des Westens berücksichtige, daß die deutsche Spaltung keinen Friedensschluß erlaube. Das dürfe nicht „jeden Fortschritt“ blockieren. Dringende Regelungen seien vorab zu treffen. Der Vorvertrag sollte nicht nur „die vordringlichsten Bestimmungen des Friedensvertrages enthalten“, sondern zugleich „auf die Beseitigung der schlimmsten Auswüchse der gefährlichen Entwicklung Westdeutschlands abzielen.“ Die Bonner Regierung sollte „in Schwierigkeiten gestürzt werden“. Insgesamt war an einen „bedeutende[n] Schritt“ zur Gewährleistung der „friedlichen Entwicklung Deutschlands“ im Sinne der SED gedacht.

Eine derartige Ausrichtung ließ keine Übereinkunft erwarten. Weitere Formulierungen machten das zusätzlich klar. Zwar wurde zugestanden, die Mitgliedschaft beider deutscher Staaten solle vom Vorvertrag unberührt bleiben, doch sollten die Westmächte zu Verhandlungen mit Zielsetzungen verpflichtet werden, die sie ablehnten: Friedensvertrag, Abzug der westlichen Truppen aus West-Berlin und der Bundesrepublik, Transformation von Staat und Gesellschaft in Westdeutschland gemäß dem Potsdamer Abkommen (das nach östlicher These eine Umwälzung wie in der DDR festgelegt hatte) und Verbot der von Bonn angeblich betriebenen „Kriegs- und Revanchehetze“. Ulbricht rechnete nicht mit der An-

18 Kratkaja zapis' peregovorov. S partijno-pravitel'stvennoj delegaciej GDR 9 ijunja 1959g., 27.6. 1959 (Datum der Niederschrift), AVPRF, 0742, 4, 31, 33, Bl. 81.

19 Die UdSSR gestand jedoch der DDR im Juni $1959 \mathrm{zu}$, den Bediensteten der ausländischen Militärmissionen in West-Berlin die Benutzung der Landwege zu verweigern. Das erschien möglich, weil die westlichen Rechtsansprüche sich nicht auf diesen Teil des Verkehrs bezogen (Anlage zum Schreiben von V. Kuznecov an das ZK der KPdSU, 5. 6. 1959, AVPRF, 0742, 4, 31, 33, Bl. 28). Bei den Militärmissionen handelte es sich um Vertretungen von Kriegsgegnern Deutschlands im Zweiten Weltkrieg, die ursprünglich beim Kontrollrat akkreditiert gewesen waren und inzwischen bei den westlichen Besatzungsbehörden registriert waren und konsularische Funktionen ausübten. Die SED-Führung suchte Druck auszuüben, um eine Übertragung von deren Tätigkeit auf diplomatische Vertretungen zu erreichen, die entweder bei der DDR bereits bestanden (im Fall der Warschauer-Pakt-Staaten und Jugoslawiens) oder nach ihrer Ansicht eingerichtet werden sollten (im Fall der neutralen Länder und der NATO-Mitglieder). 
nahme dieses Programms. Er beabsichtigte vielmehr ausdrücklich eine Wiederbelebung der Diskussion über den Friedensvertrag, also die Erneuerung der antiwestlichen Kampagne. ${ }^{20}$

Der Vorschlag lief darauf hinaus, die sowjetische Politik der Verständigung mit den Westmächten zu diskreditieren. Chruschtschow sollte einsehen, daß diese auch durch „Kompromiß“-Offerten nicht zur Erfüllung der gestellten Forderungen zu bewegen seien. Im Kreml ließ man sich freilich auf dieses Spiel nicht ein und lehnte es ab, den Vorvertrag zum Thema von Verhandlungen mit den Westmächten zu machen. Ulbricht änderte daraufhin die Taktik und hielt Chruschtschow am 30. November 1960 vor, er müsse bei der Propagierung des Friedensvertrags Vorsicht walten lassen. In der Bevölkerung habe sich die Ansicht verbreitet, in Moskau werde nur geredet, aber nichts getan. Das konnte Chruschtschow nicht gelten lassen. Er hakte ein, Ulbricht sei doch selbst damit einverstanden gewesen, daß man nach der geplatzten Pariser Gipfelkonferenz vom Mai auf den Vertragsabschluß verzichtet habe. Der SED-Chef erwiderte, das sei zwar damals richtig gewesen, doch sei die Lage mittlerweile schwierig geworden. Der sowjetische Führer sah sich genötigt, das seitherige Zögern zu rechtfertigen, und erklärte, wenn er den Separatvertrag auf die Tagesordnung gesetzt hätte, wäre der fatale Eindruck entstanden, er habe das Gipfeltreffen platzen lassen, um dafür einen Vorwand zu finden. Das Abwarten sei mit „gewaltigem Erfolg“ belohnt worden, wie Gespräche mit Vertretern der Westmächte und sogar der Bundesrepublik ${ }^{21}$ zeigten. Für 1961 stellte er in Aussicht, dem Westen ein Abkommen zu „gewähren“, das den Übergang zur Umwandlung West-Berlins in eine „Freie Stadt“ herstelle. Werde das Angebot abgelehnt, wolle er den Separatvertrag mit der DDR abschließen. Bis dahin sollte Ulbricht auf eigenmächtige Schritte verzichten.22

Der ostdeutsche Parteichef traute der Zusicherung nicht und berief sich darauf, daß die UdSSR den Standpunkt bestätigt habe, es gebe kein Vier-Mächte-Abkommen, das zu berücksichtigen wäre. Sogar die Westmächte hätten anerkannt, daß im Westteil der Stadt eine anomale Lage bestehe. Demnach war in Berlin kein besonderer Status zu respektieren. Indirekt kritisierte Ulbricht die Haltung der UdSSR mit dem Hinweis, Adenauer habe seit der sowjetischen Festlegung im November 1958 zwei Jahre gewonnen und diese Zeit zu einer „Kampagne für die Verteidigung Westberlins“ genutzt. Die einschränkende Bemerkung, die Staaten und Völker hätten sich freilich durch die Verzögerung an die Notwendigkeit einer Regelung gewöhnt, die sich nicht gegen die Hauptstadt der DDR richte, verschleierte

20 Vorschlag für den Abschluß eines Vorfriedensvertrages mit beiden deutschen Staaten (handschriftlich von Ulbricht abgezeichnet), 26. 1. 1960, SAPMO-BArch, DY 30/3507, B1. 26-30.

21 Chruščëv bezog sich hier auf eine kürzliche Unterredung mit Botschafter Kroll, dessen Auffassungen freilich oft in erheblichem Ausmaß vom Standpunkt der Bundesregierung abwichen.

22 Sowjetisches Protokoll des Treffens von N. S. Chruščëv und W. Ulbricht, 30. 11. 1960, in: Hope M. Harrison, Ulbricht and the Concrete „Rose“. New Archival Evidence on the Dynamics of SovietEast German Relations and the Berlin Crisis, 1958-1961, Working Paper No. 5, Cold War International History Project, Woodrow Wilson International Center for Scholars, Washington/DC, Mai 1993, Anlage A; Aktenvermerk über die Unterredung von W. Ulbricht mit N. S. Chruščëv, 30. 11. 1960, SAPMO-BArch, DY 30/3566, B1. 83. Der ostdeutsche Aktenvermerk gibt den Inhalt des Gesprächs nur teilweise wieder und enthält, wie der Vergleich mit der Wortwechselaufzeichnung des sowjetischen Protokolls vermuten läßt, sogar mißverständliche Angaben, bringt aber an einigen wenigen Stellen zusätzliche Ausführungen. 
den Vorwurf etwas. Wie unzufrieden Ulbricht war, zeigt sein Fazit, die Schwierigkeiten im Osten Berlins seien stärker gewachsen als im Westen der Stadt. Man müsse „die Lage real einschätzen“ und „daraus eine Reihe Konsequenzen ziehen“. Er fügte hinzu, der „Einfluß der Friedenskräfte in Westdeutschland“ wachse; „sehr langsam“ erfolge dort eine „Neugruppierung der politischen Kräfte“, und es sei eine zunehmende Distanz der Jugend zum Staat zu erkennen. Damit eröffne sich eine „reale Perspektive“ zur Gewinnung der westdeutschen Bevölkerung. ${ }^{23}$ Glaubte Ulbricht das wirklich, oder wollte er nur das düstere Bild etwas aufhellen?

Der SED-Chef wollte auch dem Kreml Anstöße zum Handeln geben. An die Stelle des geforderten Friedensvertrags zwischen Deutschland und allen Staaten der Anti-Hitler-Koalition könne als „Kompromiß“ ein Vertrag nur mit den Ländern treten, die dazu bereit seien. Man brauche nicht unbedingt darauf zu bestehen, daß die Westmächte die DDR durch einen Friedensschluß förmlich anerkennten, wenn man auch anders zur entmilitarisierten Freien Stadt WestBerlin komme. Als „weiterer Kompromiß“ sei ein „Übergangsfriedensvertrag mit beiden deutschen Staaten“ möglich. Dieser sollte die Zweistaatlichkeit und die Grenzen festschreiben, „Überreste des zweiten Weltkriegs“ wie insbesondere die Vorbehaltsrechte der Westmächte für Deutschland als Ganzes und West-Berlin beseitigen, die Vier-Mächte-Organe einschließlich der Luftsicherheitszentrale abschaffen, die westliche Truppenpräsenz in West-Berlin durch die sowjetischerseits in Genf angebotene Regelung ersetzen und den „westlichen Privilegien“ auf den Verbindungswegen ein Ende bereiten.

Als taktische Konzessionen hielt Ulbricht eine zeitlich begrenzte Hinnahme der Bindung der „Freien Stadt“ an die westdeutsche Währung und eine Zusicherung an den Westen für denkbar, die DDR werde ihren Bestimmungen für die Abwicklung des Transitverkehrs die Vereinbarungen von 1949 zugrunde legen. Für unannehmbar hielt er dagegen das westliche Verlangen, den Verkehr in irgendeiner Form der Aufsicht einer Vier-Mächte-Kommission zu unterstellen. Auch müsse der Zivilverkehr völlig aus den vierseitigen Vereinbarungen herausgehalten werden. Dazu könne man höchstens eine außervertragliche „Empfehlung“ abgeben. Zugleich müsse der UdSSR während der Übergangszeit, in der sich noch westliche Vertreter in West-Berlin befanden, eine dortige Beobachtermission zustehen. ${ }^{24}$ In einer Unterlage für Gespräche mit der UdSSR wurden einzelne Punkte näher konkretisiert. ${ }^{25}$ Vorabregelungen dieser Art erklärte der Kreml in den folgenden Konsultationen fast durchweg für „nicht zweckmäßig“. Lediglich über eine „ordentliche Bezahlung“ von DDR-Dienstleistungen durch die Westmächte (wie sie vor allem beim West-Berlin-Transit erbracht wurden) bestand Übereinstimmung. ${ }^{26}$

23 Ausführungen von W. Ulbricht laut Stichwort-Protokoll der Beratung des Politbüros der SED, 4. 1. 1961, SAPMO-BArch, DY 30/J IV 2/2/743, Bl. 7-17.

24 O. Winzer an W. Ulbricht (mit Anlagen), 10. 1. 1961, SAPMO-BArch, DY 30/3508, Bl. 1-25.

25 Ausarbeitung ohne Überschrift und Verfasser (mit handschriftlichen Bemerkungen Ulbrichts), 16. 1. 1961, SAPMO-BArch, DY 30/3508, Bl. 37-46.

26 Überlegungen, die während der Konsultation zum Ausdruck gebracht wurden, o.D. [2. Januarhälfte 1961], SAPMO-BArch, DY 30/3508, B1. 26-36. 


\section{Dissens über die Geltung von Vier-Mächte-Rechten auf DDR-Gebiet}

Dem Kreml schien eine genaue Abstimmung mit Ost-Berlin vor allem dann zwingend, wenn Fragen des Vier-Mächte-Status berührt wurden. Das galt vor wie nach Ausbruch der Berlin-Krise. Am 2. Mai 1958 verfügte die Regierung in Ost-Berlin eine starke Gebührenerhöhung für fremde Schiffe auf ihren Wasserstraßen. Die drei westlichen Staaten protestierten bei der UdSSR. Das Vorgehen lasse sich nicht mit Unterhalts- und Verwaltungskosten rechtfertigen und schränke die normale Transporttätigkeit durchfahrender Schiffe aus West-Berlin und der Bundesrepublik empfindlich ein. Die sowjetische Führung, deren Billigung Ulbricht vermutlich zuvor eingeholt hatte, wies den Einspruch zurück und lehnte das Verlangen ab, eine Aufhebung der Maßnahme zu veranlassen. Die DDR besitze „in vollem Umfang Jurisdiktion über das Territorium, das sich unter ihrer Souveränität befindet.“ Im übrigen liege keine Einschränkung der normalen Transporttätigkeit vor. Es gehe um eine Angelegenheit „rein kommerziellen Charakters“.27 Die Verpflichtung zur Aufrechterhaltung des Güterverkehrs nach West-Berlin wurde dabei nicht grundsätzlich in Abrede gestellt; der Schaden für die Stadt ließ sich durch westdeutsche Finanzzuschüsse beheben. Bei allem Widerwillen konnten, wie man vermutlich in Moskau vorausgesehen hat, die Westmächte daher die Änderung hinnehmen.

In anderen Fällen fand die SED-Führung kein Gehör in Moskau. Nachdem sie im Februar 1959 die Forderung angemeldet hatte, daß die seit 1945 bestehenden Vier-Mächte-Einrichtungen, vor allem die Militärmissionen der Westmächte in Potsdam, aufgrund des bevorstehenden Friedensvertrages zu beseitigen seien, ${ }^{28}$ erklärte sie nach dem eingetretenen Verzug, damit müsse schon vorher Schluß gemacht werden. Mehr als alles andere hätten die beim Oberkommando der sowjetischen Truppen akkreditierten Missionen ihre Berechtigung verloren und seien unverzüglich aufzulösen. Sie waren Ulbricht wegen ihres Rechts auf freie, unbehelligte Bewegung auf dem Territorium der DDR seit langem ein Dorn im Auge. Ihr Status widersprach dem Anspruch auf uneingeschränkte Souveränität und gestattete den Westmächten eine weithin ungehinderte Aufklärungstätigkeit. Der Kreml ließ zwar nicht gelten, daß es zwischen den Truppen der UdSSR und der Westmächte auf Besatzungsrecht gegründete Beziehungen gebe, hielt aber die bestehende Regelung für notwendig, weil umgekehrt die Sowjetunion bei den Stäben der drei Westmächte Militärmissionen unterhielt. Deren Existenz sollte nicht gefährdet werden. Mit dem Hinweis, der UdSSR dürften keine Nachteile entstehen, wurde das Ersuchen abgelehnt. ${ }^{29}$

Die Militärmissionen waren demnach so lange zu dulden, wie sie und andere Institutionen der frühen Nachkriegszeit nicht insgesamt durch den Friedensvertrag beseitigt wurden. Bis dahin waren sie weiter $\mathrm{zu}$ respektieren. Die sowjeti-

27 D. Bruce an M. Pervuchin, 16. 5. 1958, PA/MfAA, A 133, Bl. 105 (dte. Übers. aus dem Russ.), 112 f. (russ. Übers. des engl. Originals); M. Pervuchin an D. Bruce, o.D. [2. Hälfte Mai 1958], PA/ MfAA, A 133, Bl. 111.

28 Dorothee Mußgnug, Alliierte Militärmissionen in Deutschland 1946-1990, Berlin 2001, S. 55 f.

29 V. Kuznecov an das ZK der KPdSU (mit Anlage), 5. 6. 1959, AVPRF, 0742, 4, 3, 33, Bl. 28 f. 
schen Möglichkeiten zur Aufklärung auf westdeutschem Gebiet durften keinesfalls in Frage gestellt werden. Nur wenn dieses Risiko nicht bestand, war die sowjetische Seite bereit, auf die ostdeutschen Wünsche einzugehen. Das schien der Fall zu sein, als ihr im Juni 1958 amerikanische Piloten, die unbeabsichtigt in den Luftraum der DDR geraten und dort abgeschossen worden waren, in die Hände fielen. Ungeachtet entgegenstehender Abmachungen mit den Westmächten wurden sie den Sicherheitsorganen der DDR überstellt. Man glaubte, deren Zuständigkeit mit der Behauptung, diese seien von Anfang an in ostdeutschem Gewahrsam gewesen, begründen zu können. Ost-Berlin suchte durch Freigabeverhandlungen mit den USA eine Bestätigung ihrer uneingeschränkten Souveränität auf ihrem Territorium zu erlangen. Im Einvernehmen mit dem Kreml machte sie geltend, eine „Einmischung sowjetischer Militärs“ komme nicht in Frage. Hätte Washington das akzeptiert, wäre die Rechtsgrundlage der westlichen Militärmissionen erschüttert worden. Die Amerikaner weigerten sich. Nach langem Hin und Her kam es zu einem Kompromiß: Die USA traten über das Rote Kreuz mit DDR-Behörden in Verbindung. ${ }^{30}$

Als Anfang 1960 die SED-Führung in Moskau darauf drang, die westlichen Missionen seien ihrer Aufsicht zu unterstellen, sah der Kreml das Risiko eines schweren Konflikts mit den USA und lehnte ab. Eine Änderung sei ausgeschlossen; die Sache sei durch Vereinbarungen mit den Westmächten festgelegt. Andernfalls wäre ein Ende der sowjetischen Militärmissionen bei den westlichen Truppenbefehlshabern in der Bundesrepublik zu erwarten. ${ }^{31}$ Das kam für Moskau nicht in Betracht. Um ihren Kontrollanspruch durchzusetzen, dekretierte die DDR-Regierung am 3. Februar 1960, die Militärmissionen der Westmächte seien künftig nicht mehr beim Oberkommando der Sowjetstreitkräfte, sondern bei ihr akkreditiert. Die bisherigen Ausweise seien ungültig und müßten durch neue, von ihr ausgestellte Personaldokumente ersetzt werden. Die UdSSR rügte intern, daß die Regeln der Vorauskonsultation verletzt worden seien, ${ }^{32}$ wahrte aber nach außen hin die Solidarität mit dem Verbündeten. ${ }^{33}$ Die USA und Frankreich erhoben sofort Einspruch bei den sowjetischen Behörden und erklärten, wenn nicht weiter wie bisher verfahren werde, sähen sie nur die Möglichkeit, ihre Vertreter zurückzuziehen, was die Schließung der Missionen der UdSSR in der Bundesrepublik bedeuten würde. Das blieb ohne Wirkung. Erst als - zuerst Frankreich, danach auch die angelsächsischen Mächte - die Bewegungsfreiheit der sowjetischen Verbindungsoffiziere auf den jeweiligen Dienstort beschränkten, sah sich die UdSSR zu der Aufforderung an die DDR bemüßigt, „die bislang gültigen Papiere für die amerikanische, britische und französische Militärmission vorläufig unverändert zu belassen.“ Daraufhin sah sich diese zum Einlenken genötigt, und die

30 D. Mußgnug, a.a.O., S. 131-143; Gespräch M. G. Pervuchin - W. Ulbricht, 23. 6. 1958, RGANI, 5, 49, 76, Bl. 146.

31 Aktenvermerk über Gespräch zwischen dem stellv. Außenminister Schwab und Botschaftsrat Seljaninov, 8. 8. 1958, PA/MfAA, A 133, Bl. 162-166.

32 Gespräch O. Seljaninova - G. König/P. Florin, 28. 1. 1960, RGANI, 5, 49, 288, Bl. 39 f.

33 Daraus hat Dorothee Mußgnug, die ihre Ausführungen nur auf ostdeutsche und westliche Archivquellen stützt, den irrigen Schluß gezogen, es habe sich um eine originär sowjetische Maßnahme gehandelt (D. Mußgnug, a.a.O., S. 147-153). 
westlichen Staaten hoben die Beschränkungen für die Militärmissionen in Westdeutschland auf. 34

Ulbricht hielt jedoch an seiner Absicht fest und wies die Sicherheitsorgane der DDR an, bei nächster Gelegenheit gegen die westlichen Offiziere im Lande vorzugehen. Als am 21. Juni 1960 Wagen der britischen Militärmission ein Gebiet befuhren, in dem die Volkspolizei Übungen abhielt, und auf Stoppbefehle nicht reagierten, verhinderte die ostdeutsche Seite Aufnahmen mit Gewalt und beschlagnahmte die Fotoausrüstungen. Den Protest des Befehlshabers der Rheinarmee beantwortete der Befehlshaber der Sowjettruppen in Deutschland mit dem Hinweis, Handlungen wie Verletzung von Sperrgebieten, Eindringen in Übungsbereiche und Fotografieren militärischer Objekte könnten zu „unliebsamen Folgen“ führen. Es sei Sache der anderen Seite, durch „unbedingte Achtung der Gesetze und Bestimmungen der DDR “ künftig Zwischenfälle zu vermeiden. ${ }^{35}$ Damit blieben zwar Existenz und Status der Militärmissionen grundsätzlich unangetastet, doch wurde das SED-Regime in der restriktiven Auslegung von deren Rechten unterstützt. Ulbrichts Appell an Chruschtschow vom Januar 1961, die Vereinbarung über die Militärmissionen überhaupt aufzuheben, blieb dagegen erfolglos. ${ }^{36}$

In folgenden Konsultationen weigerte sich die UdSSR, den Status der westlichen Militärmissionen in der DDR und die Regelungen auf den Transitstrecken zu ändern. Nur wenn die Militärfahrzeuge von der vorgeschriebenen Route willkürlich abgewichen seien, sollten die ostdeutschen Behörden ihnen Anweisungen geben können. Werde eine Verletzung der Ordnung festgestellt, sei „zur Vermeidung von Komplikationen“ eine Abstimmung mit der sowjetischen Seite erforderlich. Auf der gleichen Linie lag, daß die Sowjetunion der DDR zwar zugestand, daß ihre Gesetze auch für westliche Militärangehörige gälten, sie aber zugleich dazu verpflichtete, im Falle von Verstößen „entsprechend den Umständen zu handeln, wobei in den notwendigen Fällen zwischen unseren Vertretern Kontakte unterhalten werden“. ${ }^{37}$ Diese Regelung war dazu bestimmt, die sowjetische Kontrolle über das ostdeutsche Vorgehen zu gewährleisten. Die damit verbundene Erwartung, daß es künftig keine Konflikte mit den Westmächten wegen Übergriffen der DDR gegen Angehörige der Militärmissionen mehr geben werde, erfüllte sich freilich nicht. ${ }^{38}$

Als Botschafter Perwuchin Ulbricht am 20. März 1961 eröffnete, das Verteidigungsministerium der UdSSR habe die Absicht, die über die Militärmissionen und Truppenstäbe hergestellten Kontakte zwischen den sowjetischen Streitkräften und den amerikanischen Verbänden in Deutschland zu verbessern, wagte der

34 Jean E. Smith, Der Weg ins Dilemma. Preisgabe und Verteidigung Berlins, [West-]Berlin 1995, S. $200 \mathrm{f}$.

35 Botschafter Pervuchin übermittelte am 4. 7. 1960 Ulbricht den Text dieses Schreibens von Armeegeneral Jakubovskij an General Cassels, SAPMO-BArch, DY 30/3683, B1. $24 \mathrm{f}$.

36 D. Mußgnug, a.a.O., S. 62.

37 Überlegungen, die während der Konsultation zum Ausdruck gebracht wurden, o.D. [2. Januarhälfte 1961], SAPMO-BArch, DY 30/3508, Bl. 26-36.

38 R. Malinovskij/M. Zacharov an das ZK der KPdSU (mit Anlage), 24. 3. 1962, RGANI, 5, 30, 399 , Bl. 78-79; R. Malinovskij/M. Zacharov an das ZK der KPdSU, 31. 3. 1962, RGANI, 5, 30, 399, Bl. 81 . 
SED-Chef keinen offenen Widerspruch, versuchte jedoch, dem eine Richtung in seinem Sinne zu geben. Er erklärte daher sein Einverständnis und fügte hinzu, er betrachte das als ersten Schritt zur Herstellung engerer Fühlungnahmen zwischen beiden Oberkommandos, welche die Militärmissionen überflüssig machen würden, so daß diese aufgelöst werden könnten. Nach Perwuchins Antwort ging es aber darum, die Kontakte mit Hilfe der Militärmissionen auszuweiten. Die Frage ihrer Liquidierung stelle sich erst künftig im Zusammenhang mit der Liquidierung der Überreste des Zweiten Weltkrieges insgesamt. Ulbricht fügte das Petitum hinzu, daß dies „in einer nicht allzu fernen Zukunft“ der Fall sein solle, und machte geltend, die gewünschte Ausweitung der Kontakte müsse auf die Ebene der Oberbefehlshaber und Armeegruppenstäbe gehoben werden. Dann würden die Militärmissionen keinen Sinn mehr haben. ${ }^{39}$ Diese und ähnliche Darlegungen beeindruckten den Kreml nicht: Die westlichen Militärmissionen in der DDR blieben noch bis 1990 bestehen, weil die UdSSR ihre analogen Spionagemöglichkeiten in der Bundesrepublik nicht gefährden wollte.

\section{Beginnende Konflikte wegen des Status von Ost-Berlin}

Ulbricht suchte unablässig die Souveränität seines Staates zu erweitern. Daher waren ihm die Überreste des 1945 für Berlin festgelegten Vier-Mächte-Status in der „Hauptstadt der DDR“, an denen die UdSSR aus Rücksicht auf die Westmächte festhielt, ein Dorn im Auge. Zu den mißliebigen Residuen gehörte das freie Passieren der Sektorengrenze. Ende August 1960 nahm der SED-Chef die „Revanchistenkundgebungen“ des Vertriebenenverbandes von Anfang September in West-Berlin zum Anlaß, den Kreml um die Erlaubnis zu ersuchen, außer einer Gegenkampagne auch eine Schließung der Grenze für die Teilnehmer des Treffens durchzuführen. Er bat darüber hinaus zu prüfen, ob es möglich sei, für die gleiche Zeit anzuordnen, daß Bürger der Bundesrepublik den Ostteil der Stadt nur mit einer „ordentlichen Aufenthaltsgenehmigung“ betreten dürften. Mit dem Hinweis, das müsse gründlich überlegt werden, denn diese Maßnahme bedeute die „allmähliche Einführung der Einreisegenehmigung in die Hauptstadt der DDR für westdeutsche Bürger", machte Ulbricht deutlich, daß es ihm um mehr als einen nur augenblicksbedingten Schritt ging. ${ }^{40}$

Moskau antwortete positiv. ${ }^{41}$ Am 31. August erhob die DDR-Regierung daraufhin öffentlich Einspruch „gegen den Mißbrauch Westberlins für Kriegs- und Revanchehetze“ und verfügte, daß Westdeutsche während der Vertriebenentagung nur mit spezieller Erlaubnis die Sektorengrenze passieren durften. ${ }^{42}$ Die

39 Gespräch M. G. Pervuchin - W. Ulbricht, 20. 3. 1961, RGANI, 5, 49, 377 (rolik 8978), Bl. 18 f.

40 Handschriftlich erteilter Auftrag W. Ulbrichts an A. Neumann zur Formulierung eines Vorschlags, der „auf der Parteischiene“ nach Moskau gehen sollte, 21. 8. 1960 (mit Erledigungsvermerk 24.8.), SAPMO-BArch, DY 30/3291, Bl. $12 \mathrm{f}$.

41 V. Kočemasov an V. Zorin, 29. 8. 1960, AVPRF, 0742, 5, 41, 54, Bl. 66. Der einzige Vorbehalt war, daß Personen aus sozialistischen Ländern von der Regelung auszunehmen seien.

42 Anordnung des Ministeriums des Innern der DDR über das Betreten der Hauptstadt der DDR durch Bürger der Deutschen Bundesrepublik, in: Dokumente zur Deutschlandpolitik, IV, Bd. 5 
DDR unterliege keinem Vier-Mächte-Regime, nachdem die Westmächte selbst das Abkommen darüber (durch die Mißachtung ihrer angeblichen Verpflichtungen aus dem Potsdamer Abkommen, wie unausgesprochen gemeint war) aufgehoben hätten. Sie könne „nicht zulassen, daß revanchistische und militaristische Kräfte das Westberliner Besatzungsstatut ausnutzen, um Revanchekundgebungen und Kriegshetze durchzuführen. “43 Demnach war nur eine befristete Repressalie gegen eine als Kerntruppe des „Revanchismus“ betrachtete Organisation vorgesehen. Nachdem die Tagung beendet war und die Maßnahme auslief, nutzte Ulbricht den gewonnenen Spielraum zu weiterem Vorgehen. Das DDR-Innenministerium machte am 8. September 1960 mit der Begründung, die „westdeutschen Revanchisten und Militaristen“ wollten ihre Provokationen auch künftig fortsetzen, ${ }^{44}$ den Besuch von Privatpersonen in Ost-Berlin dauerhaft von amtlicher Erlaubnis abhängig. ${ }^{45}$ Der Kreml nahm die Anordnung hin, ${ }^{46}$ äußerte aber intern Unmut. ${ }^{47}$ Dem Verzicht auf offenen Widerspruch lag die Einschätzung zugrunde, die sowjetischen Interessen seien nicht ernstlich bedroht. Da wollte man die „deutschen Freunde“ nicht bloßstellen.

Moskau sah jedoch nicht tatenlos zu, als sich die amerikanische Seite dagegen wandte, daß der Zutritt zu einer Exklave ihres Sektors von einer Aufenthaltsgenehmigung abhängig gemacht wurde. Handwerker, Monteure und andere Personen, die von West-Berlin nach Steinstücken wollten, sollten demnach das dazwischen liegende DDR-Territorium nur mit einer jeweils auszustellenden Einzelerlaubnis überqueren können. Der Politische Berater des US-Stadtkommandanten richtete daraufhin eine Beschwerde an sein sowjetisches Gegenüber. ${ }^{48}$ Perwuchin forderte Ulbricht auf, wie bisher ohne vorherigen Antrag Passierscheine ausstellen zu lassen. Aufenthaltsgenehmigungen zu erteilen, ergebe „überhaupt keinen Sinn“, wenn nur ein kurzes Stück DDR-Gebiet überquert werde. ${ }^{49}$

(1973), a.a.O., S. 191 f.; Abraham, Materialien über einige Fragen in Zusammenhang mit Berlin in den letzten Tagen, o.D. [Sept. 1960], PA-MfAA, A-617, Bl. 43.

43 Fernsehdiskussion Ulbrichts mit Eisler und Kegel, 3. 9. 1960, in: Dokumente zur Deutschlandpolitik, IV, Bd. 5 (1973), a.a.O., S. 208-219. Das Abkommen, auf das Bezug genommen wurde, war die Potsdamer Drei-Mächte-Vereinbarung vom 2. 8. 1961, das angeblich die Grundlage für die Vier-Mächte-Rechte bildete.

44 Befehl des Ministers des Innern Nr. [offengelassen]/60 (Entwurf), 6. 9. 1960, SAPMO-BArch, DY 30/3507, Bl. $340 \mathrm{f}$.

45 Text: Anordnung des Ministeriums des Innern der DDR, 8. 9. 1960, in: Dokumente zur Deutschlandpolitik, a.a.O., IV, 5, S. $229 \mathrm{f}$.

46 Vgl. Karl-Heinz Schmidt, Dialog über Deutschland. Studien zur Deutschlandpolitik von KPdSU und SED (1960-1979), Baden-Baden 1998, S. 28 f.

47 Otčët o rabote Posolstva SSSR v GDR za 1960 god (Bericht von M. Pervuchin an Ju. V. Andropov im ZK der KPdSU), 15. 12. 1960, RGANI, 5, 49, 287 (rolik 8948), Bl. 77, 80, 86, 87. Vgl. auch die Äußerung von Botschaftssekretär Kvicinskij gegenüber einem SED-Funktionär, die Maßnahme sei zwar „völlig richtig und notwendig“ gewesen, habe aber nicht die Entspannung gefördert (was nach sowjetischer Ansicht unbedingt erforderlich war) und die Einstellung der Deutschen gegenüber der östlichen Politik und der DDR zutiefst negativ beeinflußt (Gespräch Ju. A. Kvicinskij-P. Papist, 21. 10. 1960, RGANI, 5, 49, 288, Bl. 276-278).

48 Garde-Generalmajor N. Zacharov an M. G. Pervuchin, o.D. (11. 10. 1960), SAPMO-BArch, DY 30/3691, Bl. 46 f. (russ.), Bl. 40 f. (dte. Übers.).

49 M. Pervuchin an W. Ulbricht (mit Anlage), 12. 10. 1960, SAPMO-BArch, DY 30/3691, Bl. 42-44 (russ.), Bl. 36-38 (dte. Übers.). 
Die SED-Führung suchte ihre alleinige Verfügungsgewalt auf dem gesamten DDR-Territorium noch mit einem weiteren Schritt zu demonstrieren. Die westlichen Amtspersonen, die beim Betreten Ost-Berlins von jeder Kontrolle freigestellt waren, sollten ihre Ausweise vorzeigen. Die Westmächte sahen das als Beschränkung ihres aus dem Besatzungsstatus herrührenden Rechts an. In Moskau hatte man die Sorge, ein derartiger ostdeutscher Eingriff in eine Vier-Mächte-Angelegenheit könne dazu führen, daß die Westmächte umgekehrt den Bediensteten der UdSSR den Zutritt zu den Westsektoren erschwerten. Darüber brachte man in Ost-Berlin Erstaunen zum Ausdruck. Die Begründung für die vorgesehene Maßnahme wurde als ungenügend verworfen. Später erfolgte der Hinweis, die sowjetische Botschaft in Berlin habe, wie Ulbricht und Grotewohl bekannt sei, kürzlich die Weisung erhalten, die kommerzielle, kulturelle und sonstige Tätigkeit im Westteil der Stadt zu verstärken. Im Hinblick darauf könnten Schwierigkeiten entstehen, was freilich nicht unbedingt der Fall sein müsse. ${ }^{50}$ Damit lehnte der Kreml den Wunsch nicht völlig ab, wollte aber Modalitäten gewährleistet sehen, die den Westmächten keine Handhabe für Beschränkungen des sowjetischen $\mathrm{Zu}$ tritts gaben.

Ulbricht war vorsichtig genug gewesen, den Vier-Mächte-Status nicht direkt in Frage zu stellen. Er wollte nur die öffentlich vertretene Position symbolisch untermauern, Ost-Berlin sei als „Hauptstadt der DDR“ keinen besatzungsrechtlichen Beschränkungen unterworfen. ${ }^{51}$ Daher verzichtete er auf die Festlegung einer Genehmigungspflicht und war vorerst damit zufrieden, wenn sich die westlichen Beamten überhaupt einer ostdeutschen Formalität fügten. Sie sollten zunächst nur ihre amtliche Eigenschaft nachweisen. Das Verlangen war sachlich nicht zu rechtfertigen, denn sie kamen in Dienstfahrzeugen nach Ost-Berlin, die den Status der Insassen eindeutig auswiesen. Die Vorzeigepflicht diente dem politischen Zweck, das DDR-Recht auf Kontrolle prinzipiell festzustellen. ${ }^{52}$ Der Verzicht auf Stipulierung einer Genehmigungspflicht erlaubte es der UdSSR, die Maßnahme gegenüber den Westmächten herunterzuspielen. Der westliche Anspruch auf freien Zutritt wurde demnach nicht in Frage gestellt und mochte daher als unangetastet gelten. Daher wiesen die sowjetischen Behörden den Protest des amerikanischen Botschafters in Bonn dagegen zurück, daß er bei einer Fahrt über die Sektorengrenze trotz des Standers an seinem Wagen zum Vorzeigen des Ausweises genötigt worden war. Westlichen Gesprächspartnern wurde versichert, es sei nicht daran gedacht, Vertreter der drei westlichen Staaten am Betreten OstBerlins zu hindern. In Wahrung der Solidarität mit der DDR wurden aber keine Zweifel an deren Befugnis zur Regelung von Zutrittsfragen geäußert.53 Die sowjetische Seite bekundete freilich nur nach außen hin Zustimmung. Intern zeigte sie Unmut über das ostdeutsche Vorgehen. Das Erstaunen über die Behandlung des Botschafters und der Hinweis, die Vertreter der UdSSR würden beim Betreten

50 Hope M. Harrison, Driving the Soviets up the Wall. Soviet - East German Relations 1953-1964, Princeton/NJ-Oxford 2003, S. 145 f. (unter Berufung auf Berichte des DDR-Botschafters an Ulbricht vom 23. 9. 1960).

51 Abraham, Materialien über einige Fragen in Zusammenhang mit Berlin in den letzten Tagen, o.D. [Sept. 1960], PA-MfAA, A-617, Bl. 44.

52 W. Ulbricht an N. S. Chruščëv, 18. 10. 1960, BArch, DY 30/3507, Bl. $371 \mathrm{f}$.

53 K.-H. Schmidt, a.a.O., S. 30-32. 
West-Berlins keinerlei Kontrolle unterworfen, ließen die Sorge erkennen, die Westmächte könnten ebenso verfahren. Unruhe sprach auch aus der Frage, ob denn gar „eine Anweisung zur Kontrolle westlicher, in Bonn akkreditierter Diplomaten" erlassen worden sei. Auch bei anderen Gelegenheiten zeigte sich deutliches Mißfallen. ${ }^{54}$

Ulbricht reagierte empört auf die Vorhaltung, das Vorgehen der DDR-Grenzorgane könnte auf der Gegenseite Nachahmung finden. Das sei abwegig, denn ein „grundsätzlicher Unterschied“ bleibe dabei außer Betracht. Die UdSSR und die Volksdemokratien seien mit der DDR durch Freundschaftsverträge verbunden, und auch die Bundesrepublik und die West-Berliner Behörden hätten diplomatische Beziehungen zur Sowjetunion. Dagegen forderten die USA „unkontrollierte Einreise in die Hauptstadt der DDR, um zu demonstrieren, daß sie die DDR nicht anerkennen." Er sehe nicht, daß die Kontrolle westlicher Diplomaten durch ostdeutsche Organe zu Schwierigkeiten für die UdSSR in West-Berlin führen könnte. Er berief sich darauf, daß sich auch Moskau gegen die These wende, Ost-Berlin unterliege einem Vier-Mächte-Status. Folglich könnten daraus keine Forderungen gegen die DDR abgeleitet werden.55 Damit ignorierte er die Sorge, sein Vorgehen könne unabhängig von der eigenen Interpretation der Rechtslage Gegenmaßnahmen der Westmächte provozieren.

Ulbricht stellte Chruschtschow die Frage, wie zu verhindern sei, daß die Westmächte und die Bundesrepublik „den nicht mehr bestehenden Viermächte-Status ausnutzen, um in der Hauptstadt und in der DDR Einfluß zu gewinnen." Die Bonner Regierung schaffe in West-Berlin vollendete Tatsachen und baue die Stadt „Zu ihrem vorgeschobenen Stützpunkt für ihre Revanchepolitik, für Agententätigkeit gegen die sozialistischen Länder und zur Organisierung der Republikflucht aus der DDR“ aus. Erweiterungen des Zug- und Flugverkehrs dorthin brächten ihr Vorteile ohne Gegenleistungen an die DDR. Trotzdem werde - so der Vorwurf an die sowjetische Adresse - „in der Hauptstadt der DDR der nicht mehr bestehende Viermächte-Status weitgehend beibehalten. "Westdeutsche Abgeordnete, Agenten und Bischöfe könnten, ebenso wie die Besatzungstruppen der Westmächte, „ohne Kontrolle einreisen, sich frei bewegen und auftreten“. Die westliche Forderung nach Einhaltung des Vier-Mächte-Status Gesamt-Berlins ziele auf die Anerkennung einseitig geschaffener Tatsachen ab, was seit der Wiederaufrüstung Westdeutschlands und dem „aggressiven Auftreten“ Bonns nicht mehr „möglich“ sei. Wie er Chruschtschow erklärte, waren die Westdeutschen bei Besuchen in Ost-Berlin „anmeldepflichtig“, die westlichen Militärs und Diplomaten hatten in der Hauptstadt der DDR ihre Ausweise vorzuzeigen, und die Gesetze der DDR galten auch dort. Er verzichtete aber vorerst darauf, auf dem Stimmrecht der Ost-Berliner Vertreter in der Volkskammer zu bestehen. ${ }^{56}$

Die sowjetische Seite billigte, als in der zweiten Januarhälfte 1961 Konsultationen stattfanden, die Ausweisvorzeigepflicht für westliche Militärs und Beamte in Ost-Berlin und sprach den Gesetzen der DDR Geltung auf deren gesamtem Ter-

54 K.-H. Schmidt, a.a.O., S. 32 f.

55 W. Ulbricht an N. S. Chruščë, 18. 10. 1960, SAPMO-BArch, DY 30/3507, Bl. $371 \mathrm{f}$.

56 W. Ulbricht an Chruščëv, 22. 11. 1960, SAPMO-BArch, DY 30/3507, Bl. 377, 380 f. 
ritorium zu, unterschied aber zwischen Aufenthalten der westlichen Bediensteten in dieser Stadt und Besuchen im übrigen Land. Die Vertreter des SED-Regimes ersuchten um die Genehmigung von Maßnahmen gegen „demonstrative Fahrten“ westlicher Militärpatrouillen, welche die Verhaltensmaßregeln auf den Straßen angeblich bewußt mißachteten und ein „provokatorisches Verhalten“ gegenüber den staatlichen Organen an den Tag legten. Vor allem die Frage der westlichen Militärbusse müsse geprüft werden. Davon aber wollten die sowjetischen Gesprächspartner nichts wissen. ${ }^{57}$

\section{Weitere Konflikte wegen des Status von Ost-Berlin}

Ungeachtet aller Unbotmäßigkeit, war sich Ulbricht der Grenze bewußt, bis zu der er die Sieger- und Führungsmacht UdSSR herausfordern konnte. Mit dem Verlangen nach Vorweisen der Identitätspapiere hatte er einen Schritt gewählt, der nach aller Voraussicht weder prinzipielle Einwände noch ernste Sorgen auf sowjetischer Seite hervorrief. Das Vorgehen war rechtlich durch die amtliche Forderung nach Beseitigung aller „Überreste des Zweiten Weltkriegs“, vor allem des Berliner Okkupationsstatus, gedeckt, die keine Basis mehr für „Privilegien“ der Westmächte bot, wie die DDR seit Anfang 1959 im Kreml unwidersprochen geltend machte. ${ }^{58}$ Moskauer Bedenken, der Schritt könne sowjetischen Interessen ernstlich Abbruch tun, wurden dadurch weithin zerstreut, daß sich voraussichtlich aus der Vorzeigeforderung keine Gefahr für den sowjetischen Zutritt zu West-Berlin ergab. Aber der Vorwurf blieb bestehen, der SED-Chef habe gegen die Regel der Vorausabstimmung mit Moskau verstoßen. Das durfte nicht wieder geschehen.

Ulbricht war seitdem genötigt, diesem Verlangen zu entsprechen. Er suchte aber das sowjetische Einverständnis dadurch zu präjudizieren, daß er bei der Darstellung seiner Absichten keine genauen Angaben über die Modalitäten machte. In Moskau war man inzwischen gewarnt. Als daher der SED-Chef ,in Abhängigkeit von der internationalen Lage“ ein weiteres Mal das Recht auf Kontrolle des Zutritts demonstrieren wollte und zunächst allgemein beim sowjetischen Außenministerium vorfühlen ließ,59 läuteten dort die Alarmglocken. Das folgende Gesuch um Genehmigung einer Verordnung, der zufolge die Einreise von Bussen mit Touristen und „anderen Gruppen“ nur aufgrund einer DDR-Erlaubnis möglich sein sollte, rief bei Perwuchin den Argwohn hervor, mit den „anderen Gruppen“ seien die Militärs und Diplomaten der Westmächte gemeint, die oft in Bussen durch Ost-Berlin fuhren. Der Botschafter unterstrich, dieser Personenkreis dürfe nicht so behandelt werden wie geplant, und fügte hinzu, er müsse sich im übrigen

57 Überlegungen, die während der Konsultation zum Ausdruck gebracht wurden, o.D. [2. Januarhälfte 1961], SAPMO-BArch, DY 30/3508, Bl. 26-36.

58 Probleme im Zusammenhang mit der Übergabe der Rechte der sowjetischen Vertreter betreffend Westberlin an die Regierung der Deutschen Demokratischen Republik, 4.2. 1959, SAPMOBArch, DY 30/3505, Bl. 56-61, dazu insbesondere die Anlagen zum Alliierten Abrechnungsbüro, zum Alliierten Gefängnis in Spandau, zur Behandlung westlicher Diplomaten und Militärs in OstBerlin, zum Alliierten Reise- und Verbindungsbüro und zu den westlichen Militärmissionen in Potsdam, ebd., Bl. 62-93.

59 Gespräch M. Ja. Chošev - K. Maron, 10. 10. 1960, RGANI, 5, 49, 281 (rolik 8946), Bl. 203. 
wegen der komplizierten Sachlage noch mit Moskau beraten. Er war ärgerlich, daß dem Kreml nur eine äußerst kurz bemessene Frist für seinen Bescheid zugestanden sein sollte, und betonte, solche Regelungen könnten nur mit ausdrücklicher Billigung der UdSSR getroffen werden. 60

Die Befürchtung, die Genehmigungspflicht solle auch für Busse mit westlichen Amtspersonen gelten, erwies sich als berechtigt. Wie Ulbricht auf Nachfrage Chruschtschows hin zugab, wollte er „die in Westberlin stationierten Offiziere und Soldaten“ nicht mehr „in Autobussen nach Belieben in der Hauptstadt der DDR herumfahren“ lassen, wo sie dann „provokatorische Zwecke verfolgen“ könnten. Mit der Versicherung, er werde über den Zutritt von Ausländern und Staatenlosen zur „Hauptstadt der DDR“ erst dann entscheiden, wenn er „vorher die Zustimmung der sowjetischen Freunde eingeholt" habe, ${ }^{61}$ gab er jedoch dem Druck nach. Ein führender Diplomat der UdSSR konstatierte gleichwohl eine "gewisse Inflexibilität“ der ostdeutschen Seite, die sie „nicht immer“ Rücksicht auf die Folgen ihres Vorgehens nehmen lasse. ${ }^{62}$ Chruschtschows Mißtrauen kam etwa in der Nachfrage zum Ausdruck, ob denn die DDR etwa eine Genehmigungspflicht für die Botschafter der Westmächte in Bonn vorsehe, wenn diese mit ihrem sowjetischen Amtskollegen Deutschland-Fragen in Ost-Berlin besprechen wollten. Das stellte Ulbricht in Abrede und erklärte, diese würden, falls zuvor avisiert, „sogar ohne Kontrolle durchgelassen“ werden. Damit verband er die Anregung, auch sonst könnten die westlichen Diplomaten vom Vorzeigen ihrer Ausweise befreit werden, wenn sie sich vorher bei der DDR anmeldeten. ${ }^{63}$

Chruschtschow antwortete kurz, die Dinge sollten während Ulbrichts Moskau-Besuch erörtert werden. Bis dahin dürfe es an der Grenze zu West-Berlin keine Veränderung geben. ${ }^{64}$ Als er am 30. November mit Ulbricht zu einem Meinungsaustausch zusammentraf, bestand er darauf, daß die DDR generell keine einseitigen „Schritte zur Liquidierung der Überreste des Zweiten Weltkriegs“ unternehme. Das sei erforderlich, auch wenn die westlichen Besatzungsrechte mit der Souveränität der DDR unvereinbar seien. Andernfalls stünden eine Verschärfung der Lage und eine Störung der Verhandlungen mit den Westmächten zu erwarten. Die UdSSR dürfe ihr Wort gegenüber der anderen Seite nicht brechen, vor einem Gipfeltreffen nichts am bestehenden Zustand zu ändern. Vor allem müsse die Kontrolle an den Sektorenübergängen in der bisherigen Form bestehen bleiben. Sowjetunion und DDR sollten keine getrennten Initiativen entfalten, sondern einen Plan gemeinsamer Taktik der sozialistischen Länder vereinbaren, der

60 Aktenvermerk über Unterredung zwischen M. Pervuchin und O. Winzer, 18. 10. 1960, PA/MfAA, G-A 478, Bl. 2 f. Wie Ulbricht in dem dabei übergebenen Brief an Chruščëv ausführte, war es notwendig, daß die DDR „aktiver gegen die Förderung revanchistischer und militaristischer Provokationen in Westberlin durch die Bonner Regierung“ vorging, die „Störtätigkeit" der West-Berliner „Revanchisten und Militaristen“ unterband und deren „provokatorisches“ Auftreten in der „Hauptstadt der DDR“ verhinderte (W. Ulbricht an N. S. Chruščëv, 18. 10. 1960, SAPMO-BArch, DY 30/3507, Bl. 368f).

61 W. Ulbricht an N.S. Chruščëv, 18. 10. 1960, SAPMO-BArch, DY 30/3507, Bl. 370-372.

62 Otčët o rabote Posolstva SSSR v GDR za 1960 god (Bericht von M. Pervuchin an Ju. V. Andropov im ZK der KPdSU), 15. 12. 1960, RGANI, 5, 49, 287 (rolik 8948), Bl. 80.

63 W. Ulbricht an N. S. Chruščëv, 18. 10. 1960, SAPMO-BArch, DY 30/3507, Bl. 371. Zur Anlage siehe SAPMO-BArch, DY 30/3682, Bl. 26-30.

64 N. S. Chruščëv an W. Ulbricht, 24. 10. 1960, SAPMO-BArch, DY 30/3682, Bl. 39. 
Varianten für das Vorgehen unter verschiedenen Umständen enthalte. ${ }^{65}$ Ulbricht konnte als positives Ergebnis verbuchen, daß die UdSSR die Vorzeigepflicht gegenüber den USA voll unterstützte. Der sowjetische Stadtkommandant beantwortete die amerikanischen Proteste mit dem Hinweis, es handele sich um eine innere Angelegenheit der DDR, in die er sich nicht einmische. ${ }^{66}$

Eine weitere Kontroverse entstand wegen der Absicht des SED-Chefs, den Ost-Berliner Mitgliedern der Volkskammer den gleichen Status zu geben wie den anderen Abgeordneten, sobald im Dezember eine Sitzung des Bundestags im Westteil der Stadt einen geeigneten Vorwand biete. ${ }^{67}$ Der Kreml hielt jedoch an diesem formalen Überrest des Vier-Mächte-Status fest, um die Westmächte nicht unnötig herauszufordern, solange sie in Berlin präsent waren. Ulbricht sah sich daraufhin genötigt, das Vorhaben zurückzustellen. Er gab seinem Ärger darüber Ausdruck, der Vier-Mächte-Status in West-Berlin ständig mißachtet werde, während er im Ostteil der Stadt nach wie vor gelten solle. Diesen „unklaren Zustand“, den man lange Jahre zugelassen habe, erklärte er für nicht länger tragbar. ${ }^{68}$

Im Frühjahr 1961 drang die ostdeutsche Seite in Moskau auf Veränderungen, die, wenn man von der Forderung nach höheren Entgelten für die Dienstleistungen der DDR auf den Zugangswegen absieht, allesamt auf einen Abbau von Elementen des Berliner Vier-Mächte-Status hinausliefen: geänderte Abfertigungsmodalitäten im westlichen Militärverkehr, Einführung eines Pflichtumtauschs für westliche Besucher des Sowjetsektors, Einschränkungen des Rechtes der Westmächte auf Zutritt sowie Aufhebung der auf Übereinkünfte der Okkupationsmächte zurückgehenden Regelungen und Institutionen. Die UdSSR erklärte das in fast allen Punkten für verfrüht und machte klar, daß dem Verlangen erst entsprochen werden könne, wenn das Besatzungsrecht durch Abschluß des Friedensvertrags seine Grundlage verloren habe. Die DDR wurde darauf hingewiesen, „daß bei der Verwirklichung jeder konkreten Maßnahme weitere Konsultationen durchgeführt und miteinander Kontakte unterhalten werden müssen. “69

\section{Strittiges Verhalten gegenüber West-Berlin}

Die Führungen von UdSSR und DDR waren unterschiedlicher Meinung darüber, wie man die Ziele gegen den Westen am besten durchsetzte. Chruschtschow wollte seine Ziele möglichst durch positive Anreize erreichen, etwa indem er Kontakte knüpfte und Sympathien zu wecken suchte. Die West-Berliner sollten

65 Otčët o rabote Posolstva SSSR v GDR za $1960 \operatorname{god}$ (Bericht von M. Pervuchin für Ju. V. Andropov im ZK der KPdSU), 15.12. 1960, RGANI, 5, 49, 287, Bl. 91. Vgl. Aktenvermerk über die Unterredung von W. Ulbricht mit N.S. Chruščëv, 30. 11. 1960, SAPMO-BArch, DY 30/3566, Bl. 84.

66 Siehe z.B. I. Il'ičëv an M. Pervuchin (Übermittlung eines Telegramms von Generalmajor Zacharov), 24. 2. 1961, AVPRF, 0742, 6, 17, 5, Bl.1.

67 W. Ulbricht an N. S. Chruščëv, 18. 10. 1960, SAPMO-BArch, DY 30/3507, Bl. 373.

68 W. Ulbricht an N. S. Chruščëv, 22. 11. 1960, zitiert nach K.-H. Schmidt, a.a.O., S. 37 f.

69 Arbeitsnotizen. Überlegungen, wie sie während der Konsultation zum Ausdruck gebracht wurden, o.D. [spätestens erste Junihälfte 1961], DY 30/3508, Bl. 26-36 [Zitat auf Bl. 36]; Ministerium für Nationale Verteidigung. Operative Verwaltung, Tagebuch-Nr. Va/144/61, o.D. [22. 6. 1961], BArch-MArch, VA-01/18790, B1. 2. 
durch lockende Angebote gewonnen werden. Den ersten Schritt dazu sah er in der Zuerkennung des Freistadt-Status. Nach seiner Ansicht würdte es Zustimmung bei der Bevölkerung wecken, wenn ihre Stadt vom westlichen Besatzungsregime „befreit“ wurde und den Status einer „selbständigen politischen Einheit“ erhielt. Diese sollte durch enge wirtschaftliche und kulturelle Beziehungen allmählich in den Kreis der sowjetisch orientierten Staaten einbezogen werden. Eine ökonomische Zusammenarbeit, die nicht von unsicheren kapitalistischen Konjunkturschwankungen abhänge und mithin stabil sein werde, werde dafür eine gute Grundlage bieten. ${ }^{70}$ Im Sommer 1960 wurde die Botschaft bei der DDR angewiesen, sich um breite wirtschaftliche, kulturelle und sonstige Kontakte und vielfältige institutionelle Verbindungen mit West-Berlin zu bemühen. ${ }^{71}$ Während einer Woche des sowjetischen Films im Frühjahr 1961 war intern von künftigen „Sonderbeziehungen“ die Rede. Diese würden Bonn Grund zur Sorge [um den Erhalt der Bindungen der Stadt an die Bundesrepublik] geben. ${ }^{72}$

Ulbricht dachte anders. Er glaubte nicht an die Möglichkeit, die West-Berliner zur östlichen Seite herüberzuziehen, und setzte auf restriktive, zwangsgestützte Maßnahmen. Jede Chance, die der Stadt geboten wurde, war in seiner Sicht eine Stärkung des Feindes. ${ }^{73}$ Solange West-Berlin nicht voll unterworfen war, sah er in ihm einen politischen Fremdköper, gegen den die DDR abgeschirmt werden mußte. ${ }^{74}$ Am 22. Januar 1959 erhielt Innenminister Maron den Auftrag, bis 28. Februar „einen Vorschlag über die Neuregelung des Systems der Sicherung der Sektorengrenze innerhalb Berlins auszuarbeiten" ${ }^{75}$ Chruschtschow war damit nicht einverstanden. Er wollte alles vermeiden, was in West-Berlin Ablehnung hervorrufen und negatives Aufsehen erregen konnte. ${ }^{76}$ Perwuchin kritisierte, der Boykott der „deutschen Freunde“ gegen die Stadt habe 1948/49 im Kampf um die Kontrolle Gesamt-Berlins seine Berechtigung gehabt, seither sei jedoch „das eine oder andere im Lande passiert“. Die dadurch veränderte Lage mache es notwendig, sich „neue Aufgaben“ zu stellen.77 Die Politik der DDR trage „in der Regel einseitigen, vornehmlich administrativen Charakter“ und sei nur auf die Be-

70 V. Zubok/Z. Vodop'janova, Sovetskaja diplomatija i berlinskij krizis (1958-1962 gg.), in: M. M. Narinskij (glavn. red.), Cholodnaja vojna. Novye podchody, novye dokumenty, Moskau 1995, S. 261.

71 Otčët o rabote Posol'stva SSSR v GDR za 1960 god (Bericht von M. Pervuchin an Ju.V. Andropov im ZK der KPdSU), 15. 12. 1960, RGANI, 5, 49, 287 (rolik 8948), Bl. 85; Aufzeichnung sowjetischer Herkunft ohne Über- und Unterschrift (in dtr. Übers.), 17. 8. 1960, SAPMO-BArch, DY 30/ 3506, B1. 330.

72 Äußerungen von Botschafter Pervuchin im Gespräch mit seinem ungarischen Amtskollegen: István Rostás an Károlyi Kiss/Imre Hollai (ungar.), 25. 4. 1961, MOL 288.f.32/1961/12.ö.e., Bl. $161 \mathrm{f}$.

73 V. Zubok/Z. Vodop’janova, Sovetskaja diplomatija i berlinskij krizis (1958-1962 gg.), in: M. M. Narinskij (glavn. red.), Cholodnaja vojna. Novye podchody, novye dokumenty, Moskau 1995, S. 261.

74 Alexei Filitov, The Soviet Policy and Early Years of Two German States 1949-1961, unveröffentlichtes Manuskript, S. 14 (nach Akten aus dem RGANI).

75 Auszug aus dem Protokoll der Sicherheitskommission des Politbüros der SED vom 22. 1. 1961, BArch-MArch, VA 01/5046, B1. 69.

76 Alexei Filitov, The Soviet Policy and Early Years of Two German States 1949-1961, unveröffentlichtes Manuskript, S. 14 (nach Akten aus dem RGANI).

77 Äußerungen von Botschafter Pervuchin im Gespräch mit seinem ungarischen Amtskollegen: István Rostás an Károlyi Kiss/Imre Hollai (ungar.), 25. 4. 1961, MOL 288.f.32/1961/12.ö.e., Bl. $161 \mathrm{f}$. 
schränkung der Bewegungsfreiheit zwischen beiden Teilen der Stadt ausgerichtet. Dagegen würden die „breiten Möglichkeiten“ der legalen Arbeit in West-Berlin nicht genutzt. Auf diese Weise könne man bei der Bevölkerung keine Erfolge erzielen. ${ }^{78}$

Ulbricht wurde noch mißtrauischer, als die Gespräche Chruschtschows mit Eisenhower in Camp David Ende September 1959 die Aussicht auf eine sowjetisch-amerikanische Verständigung zu eröffnen schienen. Er befürchtete ein Arrangement, das zwar der DDR die Souveränität über die Zugangswege West-Berlins gebe, aber die westliche Präsenz in der Stadt nicht beseitige und ein Transitabkommen ohne wesentliche Eingriffsmöglichkeiten der DDR vorsehe. ${ }^{79}$ Er suchte die Annäherung der zwei Großmächte durch eine Propagandakampagne aufzuhalten, welche die „feindselige Tätigkeit [der USA] gegen die DDR und die anderen Länder des sozialistischen Lagers“ thematisierte. Er traf auch innenpolitische Maßnahmen, die sich, wie die Sowjetbotschaft rügte, gegen das Bemühen um einen Brückenschlag in der Berlin-Frage richteten. Anfang 1960 schickte er nach Moskau die Schreckensmeldung, die „westdeutschen Militaristen“ planten ein Bombardement Dresdens und Leipzigs mit taktischen Raketen. Vier Monate später, nach Abbruch der Pariser Gipfelkonferenz, suchte er den Kreml zur politischen Offensive gegen West-Berlin zu überreden. ${ }^{80}$

78 Otčët o rabote Posolstva SSSR v GDR za $1960 \operatorname{god}$ (Bericht von M. Pervuchin für Ju. V. Andropov im ZK der KPdSU), 15.12. 1960, RGANI, 5, 49, 287, Bl. 88-90; Aufzeichnung des tschechoslowakischen Außenministers David über Chruščëvs Ausführungen auf der ordentlichen Sitzung des Politisch Beratenden Ausschusses des Warschauer Pakts in Moskau am 4. 2. 1960, 20. 2. 1960, in: Michal Reiman/Petr Luňák, Studená válka 1954-1964. Sovětské dokumenty v českých archivech, Brünn 2000, S. 145-147.

79 Diese Möglichkeit deutete Botschafter Pervuchin in einem Gespräch mit seinem ungarischen Amtskollegen an: István Rostás an Karolyi Kiss/Imre Hollai (ungar.), 25. 4. 1961, MOL 288. f. 32/ 1961/12.ö.e., Bl. 160.

80 V. Zubok/Z. Vodop'janova, a.a.O., S. 265 f. 